PSYCHOLOGY

\title{
SOCIAL-PSYCHOLOGICAL OUTCOMES OF COACHING COOPERATION FOR INTERNALLY DISPLACED PERSONS WITH LOW AND MODERATE LEVELS OF LIFE SUCCESSFULNESS
}

\author{
Borovynska Iryna, PhD Student, Institute for Social and Political Psychology, Kyiv, Ukraine, \\ ORCID ID: https://orcid.org/0000-0002-7280-0424 \\ DOI: https://doi.org/10.31435/rsglobal_conf/25122020/7310
}

\begin{abstract}
The article is dedicated to the overview of the results of coaching cooperation with internally displaced persons. In a formative experiment that occurred in the form of coaching took part thirteen IDPs with low and moderate levels of life successfulness.

For the evaluation of coaching outcomes, we used both qualitative and quantitative methods. For collecting qualitative data, we used a set of questionnaires both before and after coaching. For qualitative data collection, we used semi-structured interviews before and after coaching.

Coaching sessions were conducted from March until June 2020. Each coachee had a set of sessions dedicated to their issues connected with life successfulness and social-psychological strategies for life successfulness utilisation. The number of sessions ranged from five to ten sessions per person. The duration of each session was from thirty to sixty minutes.

After coaching cooperation, we identified changes in both qualitative and quantitative data sets, allowing us to conclude coaching effectiveness in cases connected with forced relocation and its outcomes.
\end{abstract}

Keywords: coaching, IDPs, intervention, coaching effectiveness evaluation, coaching outcomes.

Introduction. After forced relocation because of the occupation of Crimea and armed conflict in the Donbas area, many people faced with different problems. Their issues were related to adaptation, renewal of financial level and accommodation, reconstruction and attainment of social connections, experiencing trauma and other psychological, social and economic outcomes.

Researching social-psychological strategies for life successfulness, we discovered that the larger part of internally displaced persons (IDPs) with a high level of life successfulness had an experience of addressing helping professionals. During the in-depth interviews, our respondents reported that such a strategy helped them overcome psychological difficulties and get back on track.

Thus, we decided to dedicate the last part of our research to coaching evaluation as a mean of social-psychological strategies for life successfulness activation.

Main goals. The main goal of this article is to show the social-psychological effects of IDPcoach cooperation using both quantitative and qualitative means of research.

Theoretical background. Coaching is a method of intervention which is based on the cooperation of coach and coachee (client) directed on the maximisation of client's potential (Nareiman et al. 2019, ICF 2020 a) and achieving of essential goals in different spheres of life, self-awareness and personal responsibility of the participant (Passmore, Fillery-Travis 2011).

The basis for coaching is a partnership of coach and coachee, which recently is the object of numerous research (Correia et al. 2016; de Haan et al. 2016). The cooperation between coach and coachee means that both parties have their duties and obligations, and their characteristics influence the coaching effectiveness and outcomes (Boysen, 2018).

The coach role in the process is, first of all, to focus on coachee's issues and goals and to facilitate sustained behaviour change (Brotman et al. 1998). Thus, a coach is like an accompanee who helps to move from the "now" point to the desired point in the future. At the same time, the coach must have a proper set of personal qualities that help create an atmosphere of trust, assistance and support. He/she has to be intelligent, have savvy and grounded self-knowledge (Koortzen, P., Oosthuizen, R., 2010). Coach also needs to be skilled in giving feedback on the coachee's progress, stimulating consciousness and development, asking relevant probing questions, motivating the coachee by recognising his/her accomplishments.

First of all, the coachee role in the process is connected with voluntarily setting and commitment to his/her coaching goals (McGovern et al. 2001). To make coaching process effective 
coachee has to be fully present for each coaching session, complete his/her assignments between sessions, practice skills and behaviour needed for changes, consider professional coaching as an opportunity to take advantage of, take risks, (Stevens 2005) and try other strategies when needed.

As far as many IDPs are disoriented after relocation coaching could be considered as a mean of stabilisation and further development of strategies which will lead to the achievements in important life spheres.

In our previous work, we analysed unsuccessful IDPs' answers to understand what problems they usually face after forced relocation and how coaching could be applied to those problems solving. We divided all the obstacles into two main groups: intrapersonal and interpersonal. Intrapersonal set of problems are connected with personality (complexes and limiting beliefs, lack of self-confidence and self-esteem, incomprehension of own needs and interests, pessimism, inflexibility, lack of motivation and commitment, striving to escape difficulties and responsibility) and level of skills development (inability to set goals and imagine personal future, lack of planning and time-management skills; an inability to keep focus and to achieve results; an inability to overcome obstacles and difficulties; a lack of strategic thinking; an underestimation or an overestimation of one's resources (time, efforts, abilities). Intrapersonal problems are connected with the loss of habitual social environment and lack of communication after relocation, low level of communication skills, a psychological barrier connected with communication (for example, inability to ask for help), a lack of experience in forming new social environment, a lack of support, a lack of interest in other people or distrust.

As a mean of intervention, coaching could be applied to both groups of problems if a person is ready to be engaged in coaching cooperation and follow the conditions described above. Coaching could deal with typical behaviour patterns, reflection ability, invention and implementation of new behavioural strategies, overcoming limiting beliefs on both intrapersonal and interpersonal levels (Borovynska, 2020: 26)

Methods. As far as this research was a part of a bigger one connected with socialpsychological strategies for life successfulness of internally displaced persons, we involved in personal coaching 13 IDPs with low and moderate levels of life successfulness. Every participant had an opportunity to have from 5 to 10 personal coaching sessions. Before selecting people for personal coaching, we asked them to ground their need of coaching and write a list of themes (problems) that they would like to work on considering that the last ones should relate to life successfulness and social-psychological strategies for life successfulness. It was rather an important stage because the effectiveness of coaching, along with other factors depends on a person's engagement and interest. After selection, we signed up coaching contracts that included the main rules of cooperation, the list of topics we agreed to work on and the approximate dates of every session. As a sample, we used an agreement recommended by the International Coach Federation (ICF, 2020 b)

Coaching sessions for those people were free of charge. Firstly, because of their forced relocation experience and in some cases, inability to pay for coaching sessions secondly, because they agreed to take part in our research, to fill in all the needed forms before and after coaching, to be interviewed before and after coaching, and to use all those materials in our research.

All the work with IDPs were conducted from March to the beginning of June 2020.

Before and after coaching participants filled in forms which included several methodic directed on evaluation both intrapersonal and interpersonal characteristics:

- Level of Life Successfulness. We developed this questionnaire for evaluation of the level of life successfulness. It is a 39-items self-report survey that consists of questions related to six subscales which represent results in main life domains that were distinguished theoretically (Relationships with Close People, Leisure, Health, Personal Development, Social Environment, Financial-Professional Fulfillment), the scale of Social Desirability and scale which assess emotional state connected with respondents' life successfulness (Emotional Evaluation of Life Successfulness). The instrument is scored by summarizing responses for each of the seven subscales to understand the level of satisfaction with each life domain and by totaling scores of all the scales (except Social Desirability) to get the overall test result. Construct validity of the questionnaire is supported by internal consistency (alphas ranged from 0.65 to 0.85 for the seven subscales) and factor analysis showed that the six domains, as well as evaluation of emotional state, are empirically distinguishable from one another.

- Communicative Social Competence is a 100-items self-report survey which are placed in cyclic order. The questionnaire is directed on evaluating personal characteristics that help a person set 
and maintain productive contacts with other people. It consists of 8 scales (sociability, logical thinking, emotional resilience, carelessness, sensibility, independence, self-control, an inclination to antisocial behaviour) (Fetiskin, 2002: 99).

- Personal competitive ability is a bipolar self-report scale which consists of eleven statements. The technique is designed to evaluate the existent level of competitive ability, which is considered a form of interpersonal interaction under the condition of opposition towards individuals or groups achieving the same goals (Fetiskin, 2002: 82).

- Motivation for achievement is a questionnaire which helps to evaluate which aspiration to a greater extent defines a person's behaviour: a wish to achieve success or escape failure. (Fetiskin, 2002: 74).

- Diagnostic of manipulative attitude defines the extent of a person's inclination to express a manipulative attitude towards others (Fetiskin, 2002: 192).

- Perceptional evaluation of stress resistance is a technique directed on an evaluation of the type of stress resistance. There are two types of stress-resistance A (behaviour oriented on success and life achievements, permanent readiness to act, to compete, to achieve regardless circumstances. This type is identified as stress-sensitive) and B (non-aggressive, rational, non-emotional. This type is considered as stress-resistant) (Fetiskin, 2002: 175).

- Self-evaluation of ontogenetic reflection level is directed on evaluating reflection level, which includes analysis of past mistakes, successful and unsuccessful life experience (Fetiskin, 2002: 171).

- Goal. Mean. Result this questionnaire is directed on the research of action structure peculiarities. Any action could be considered as such that consists of three sequentially rotating components. This technique serves to define personal peculiarities connected with action planning, using means for achievement and result evaluation (Malkina-Pykh, 2005).

For a collection of qualitative data connected with evaluation of participants' state "before" and "after" coaching, we used semi-structured interviews which were audio or video recorded and then transcribed verbatim.

All the interviews were held at a suitable for a respondent time both personally and via online applications for video calls, such as Skype, Viber, Zoom, et cetera. Such an approach was used because some of the respondents were in other from Kyiv territories of Ukraine, and some of them were limited with time and were not able to meet personally.

For evaluation of "before" state, we used the next set of questions: Do you consider yourself a successful person? What does life successfulness mean for you? Do you utilize one of these strategies for success achievement: Support of Close People, Addressing Helping Professions Specialists, Sample Actions, Cooperation with Other People, Integration into Community, Using of Other People (manipulative behaviour), Actions Regardless Circumstances. How do you use those strategies? What are your expectations about our cooperation? What topics do you want to consider during our cooperation? What result should bring solving of those issues? If to imagine that this is our last meeting after coaching, what has changed?

For evaluation of "after" state and coaching outcomes, we used the next blocks of questions: Has something changed in the evaluation of yourself as successful in life after coaching? How do you consider life successfulness now? What is it for you now? What has changed in your utilization of social-psychological strategies for life successfulness? Have your needs been satisfied during the coaching? How have those needs been satisfied? What new skills and knowledge have you achieved? Have you felt changes in the next categories: self-understanding, self-confidence, selfefficacy, self-regulation, communication?

According to ICF standards, we conducted coaching sessions no frequently than once a week or two weeks. The sessions' duration was from 30 to 60 minutes; the average time was about 45 minutes. Between sessions, coachees usually had tasks connected with the session's topic and/or decisions taken during the session. Every coachee has his/her list of issues and topics that have limited influence on concrete factors from one side, but from the other side was individualised, aligned with ICF standards, and directed on achieving participants' personal goals.

Results and discussion. To evaluate results of coaching cooperation we first of all conducted comparative analysis of quantitative data. We used Student's t-test for linked samples and identified significant difference in the next scales: Social desirability $(\mathrm{t}=2,645, \mathrm{p}=0,021)$, Relationships with Close People ( $t=-2,755, p=0,017)$, Leisure $(t=-2,739, p=0,018)$, Life successfulness (overall test result) $(t=-2,536$, $\mathrm{p}=0,026)$, Factor $\mathrm{P}(\mathrm{t}=2,359, \mathrm{p}=0,036)$, Reflection $(\mathrm{t}=2,214, \mathrm{p}=0,047)$, Stress resistance $(\mathrm{t}=3,696, \mathrm{p}=0,003)$. 
As we can see, some of the results have a negative value (Relationships with Close People, Leisure, Life successfulness). Some results have a positive value of t-Student (Social desirability, Factor P, Reflection, Stress resistance). This peculiarity is connected with the system of scoring in different surveys. Those scales which showed negative values of t-Student are calculated with an increase in figures when a marker is improved, those which have positive values of t-Student show progress when figures are decreased. Thus, all the rates in evaluated scales were improved.

For perception convenience, we divided all rates into groups following the scoring system and showed a contrast of means before and after coaching in two diagrams.

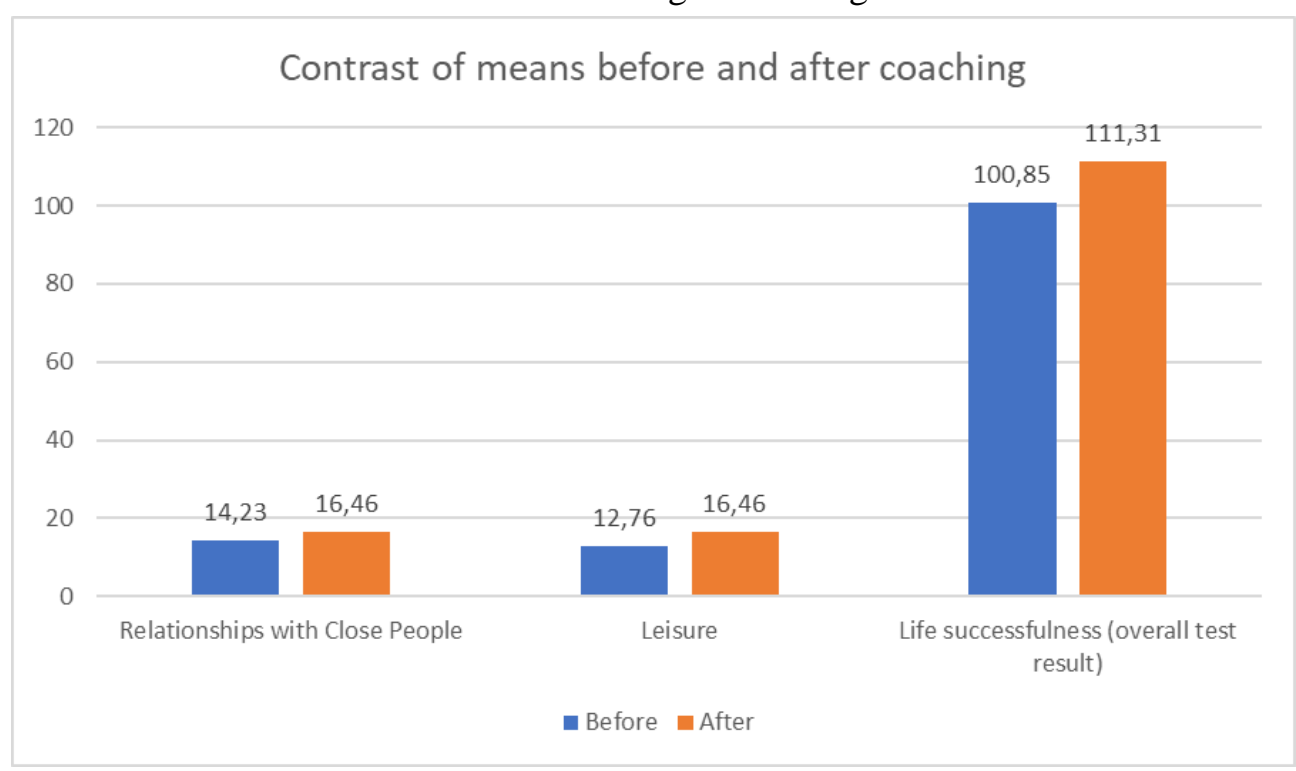

\section{Diagram 1: the growth of values after coaching}

As we can see, the overall result of life successfulness increases after coaching cooperation. We can suggest that growth occurs due to the improvement of relations with close people and leisure scales. Maybe there is a growth of other scales, but they are not statistically significant. Thus, we can say that coaching could be considered as one of the means for life successfulness increase.

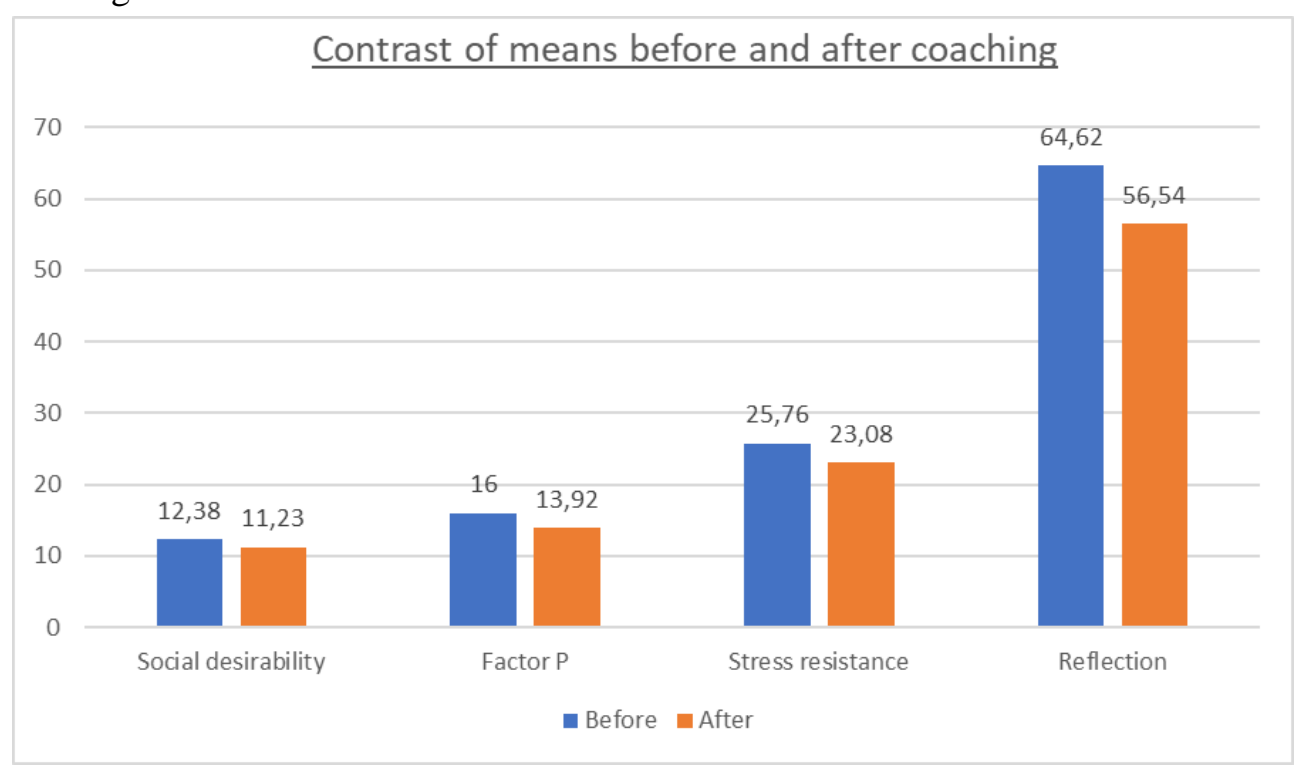

Diagram 2: the decrease of values after coaching

From the diagram above we can see a decrease of Social desirability scale that means that after coaching tendency to give social welcomed answers goes down. In our view, such results are connected with other indicator shows in this diagram. It is an ability for reflection. The scores are decreased, which means that the ability to reflect rises. When a person is self-aware, when he/she can adequately evaluate own success and failures, when he/she knows their needs, the social approval is not needed to such 
extent as it needed before. Factor $\mathrm{P}$ in communicative social competence test is responsible for the inclination to antisocial behaviour: the higher scores, the higher inclination to antisocial behaviour. As we can see from the diagram Factor $\mathrm{P}$ also decreases that means that after coaching participants are more likely to manifest pro-social behaviour, which, according to our previous research is typical for IDPs with a high level of life successfulness. One more scale that we see in the diagram is Stress-resistance, whose figures also go down after coaching, which means that stress-resistance increases.

In parallel with the quantitative evaluation of the results of coaching cooperation, we conducted the qualitative evaluation. The first category which we took for analysis was a category of "Life successfulness". We asked participants "What has changed in your understanding (feeling) of life successfulness after coaching?"

Five out of thirteen respondents gave more concrete and structured responses about their understanding of life successfulness in comparison to the responses before coaching:

Coachee_2: "Life successfulness is my realisation in every sphere of life according to the Life balance circle: personal relations, health, relations with kids, friendship and work."

Coachee_7: "It is achieving a certain level in all spheres. It is my personal development, family life, $<\ldots>$ professional, undoubtedly, and $<\ldots>$ financially-material.

One respondent reported that the parameters of success evaluation have changed after coaching.

Coachee_8: "I feel successfulness on physical and psychological levels. I feel happy, and it means that I am successful."

Several participants reported changes in their feeling of life successfulness because of their actions connected with goal setting and understanding of their needs.

Coachee_4: "The meaningfulness in goal and task setting appeared. $<\ldots>$ when you act more conscious, undoubtedly, you feel yourself more successfully."

Coachee_6: "<...>, I found a concrete goal in my life and even the way I need to follow to achieve this goal."

One participant reported that after coaching, she became more confident that she is successful, because of the feeling that any aim is reachable has appeared.

Coachee_3: "My feeling has changed. I start to see any aim more confidently and understand that it is achievable."

Some more participants reported about the growth of their life successfulness level because of the realisation of their mistakes or understanding what kept them from success achieving.

Coachee_5: " $<\ldots>$, I figured out those points that kept me from achieving that level of successfulness that I want."

Coachee_8: <...> I just have not wrapped up things connected with sales. I have not done some moments, especially haven not worked out enough such things like the target audience, and its requests."

Only one respondent reported that nothing has changed after coaching. However, there are several reasons. First, his request was connected with the launching of a business connected with service provision. Our cooperation started in March 2020 when the lockdown was provided in many countries because of COVID-19. Thus such business launching was restricted. The second reason was related to coachee's unreadiness for coaching cooperation. It was one of two cases when participants declared their readiness for coaching but were not ready for it in reality. They did not understand their real needs and waited that someone else would put efforts for their goals' achievement. Despite this, later during the post-coaching interviews, they reported some tiny results in some spheres.

The second category of our analysis was related to changes in social-psychological strategies for life successfulness.

Support of Close People

Four persons reported changes for the better.

Coachee_4: "changed for better because from one side, I started to request their (close people) support. From the other side, I feel it (support) more clearly."

Coachee_5: "for two last weeks, I started to use this strategy more often and engage my close people. $<\ldots>$ it seems that yes, it helps me more now."

Coachee_10: "Yes, they (close people) are more engaged in comparison with the coaching beginning." 
Coachee_13: "I started to say to my boyfriend what support I need. So, yes, there are changes."

Four persons reported that they changed their perception of this strategy. Two of them told that they re-evaluate support of close people another two others started to lean more on themselves.

Coachee_6: "I became another person in the question of the support perception, which is provided by my relatives."

Coachee_12: "I realised that support could be not only financial or material but also psychological, moral."

Coachee_8: "Yes, support is important, but you need to count on yourself more."

Coachee_11: "I think that I need it less now. Now I have more confidence in my force and in that what I can do."

Four respondents reported that nothing has changed in this strategy. One person reported that she had support during the coaching cooperation.

Addressing Helping Professionals. Four out of thirteen respondents experienced helping professional addressing and reported that nothing has changed in evaluating or utilisation this strategy.

Coachee_1: "This is a valid strategy. I used it before and going to use in the future".

Coachee_5: "Nothing has changed it his strategy, because I always thought that it helps."

Coachee_7: "I thought so before, and now I think the same. You cannot (understand yourself) without an attendant, without professional."

Other nine respondents who did not experience addressing helping specialists or had contradictory impression reported that this is a good strategy and that they are happy to use it.

Coachee_3: " $<\ldots>$ I really realised that this is important. $<\ldots>$ I experienced how it works and how much it gives force. It is really needed."

Coachee_4: "I recognise those professions, and I am ready to address them. It makes sense."

Coachee_6: "After addressing you, I felt on myself what is a professional approach and what is aware in his/her sphere professional. <... I am impressed by how it influenced on me."

Coachee_8: "<...> in our case I got a positive experience. It is really so. I put my brains in order. So, I consider (this strategy) positively."

Coachee_9: "Now I clearly see what I need to do and how to act."

Coachee_10: "Coaching is what I need!"

Coachee_11:"Yes, yes (this strategy is effective). It was always a view from another angle much fresher. Furthermore, I understood that I missed such a strategy."

Coachee_12: "I ensured that good professional is a genuinely excellent resource in solving personal issues. He/she helps to make an order and find a solution in different situations."

Coachee_13: "On our experience, I realised that this strategy is 100\% viable."

Sample Actions. This strategy is very interesting for analysis because it is one of the most contradictory. Most people consider sample actions as something terrible and prefer to show individualism and creativity. However, considering this strategy as appliable for a situation where you do routine actions or there already are good and checked ways of results' achievement, it is more than viable. In such cases, it saves time and efforts.

After the coaching, four people, who reported before that they do not use this strategy, said about changes (positive perception of this strategy).

Coachee_1: "If to consider you as a sample when you showed different possible reactions on the situation, I can say yes (this strategy could be utilised).

Coachee_3: "Sample actions - yes (it could be a good strategy) if you have a worthy sample. But blind copying - no."

Coachee_5: "Sometimes I use such things $<\ldots>$ but mostly lean on my methods."

Coachee_6: "If under sample actions, consider repeating after teacher $<\ldots>$ that is what I am driving at."

Two participants said that they somehow reconsidered this strategy.

Coachee_10: "It worth focusing on it, because, really, we develop schemes for some work. Thus it could be appliable".

Coachee_11: "when we are talking about routine actions naturally they are made according to the sample $<\ldots>$ in the moments of making a choice or decision $<\ldots>$ I more dive in realisation what is suitable now and what is needed to be done." 
Three people said that they used this strategy before and are going to use it in the future. Four participants reported that this strategy is not natural for them and that they will not use it in the future.

Cooperation with Others.

Seven participants out of thirteen reported that their cooperation with others has changed for the better.

Coachee_1: "I can cooperate when it is needed. However, recently I try more to take into attention my interests."

In the case of coachee_1, it could seem that there are negative changes because he started to pay more attention to his own needs which are not very good for cooperation. Nevertheless, if considering the whole context, it will be evident that such changes are positive, because before respondent tried to do everything for others, forgetting about own interests and needs.

Coachee_2: "Yes, I have it now. My friend is developing her project now, and I cooperate with her." Coachee_4: "It has changed. <...>Your example of attentive and thoughtful listening helps me a lot. I try to use it with colleagues."

Coachee_7: "The role of cooperation has grown. I even consider my pupils as partners, not like an object or subject whom I teach. $<\ldots>$ I ensured that now only teamwork could bring result."

Coachee_10: "It becomes better. <...> I started to pay more attention to it. It is Everything thanks to you and coaching."

Coachee_11: "There was an increase in communication with others. $<\ldots>$ The importance and value of conversations appeared."

Coachee_12: "Our mutual work, those situations which we considered and solutions which we found showed that cooperation could appear in very unexpected places. I think that cooperation is a background for any business."

Another five respondents said they successfully utilised cooperation before, and nothing changed in this strategy after coaching. One participant reported that he does not see a need for cooperation now.

Integration into Community. The most number of respondents answered that nothing has changed in the strategy of integration. One of the reasons is that coaching was provided during the lockdown, and there were no opportunities for any meetings or gathering of people. Everything (even parks) were closed. Many respondents said that they considered this strategy as viable and will address it after lockdown finishing.

Coachee_11: "Now I have more readiness to integrate. $<\ldots>$ but now it is not a proper time for integration. Not all are ready to meet and to communicate."

Only one participant reported progress in this strategy utilisation.

Coachee_10: "I am trying to integrate into neighbour's community. I got acquainted with one very positive lady. And together we go to the forest to collect herbs and mushrooms."

Using of Other People (manipulative behaviour). This is the second controversial strategy. Some respondents changed their mind from its utilisation towards cooperation after coaching.

Coachee_5: "It works on short distances. <... > if you want a long-term cooperation with others you need to use "win-win" strategy.

Coachee_7: "There are changes. You cannot achieve a lot utilising manipulation in a longterm. Maybe you can use some elements, but you should be directed on cooperation."

Coachee_12: "I am more sympathetic to cooperation."

Coachee_13: "I am leaning towards mutually beneficial cooperation."

Other participants, especially managers, confessed that they consider this strategy effective when working with employees.

Coachee_4: "The manager's role makes me use other people $<\ldots>$ because I as a manager need to achieve a result. $<\ldots>$ I cannot say that it is with negative connotation $<\ldots>$ when I see that person is not ready to understand what I want $<\ldots>I$ just assign step-by-step tasks which bring to my goal and performer could not see the whole aim."

Coachee_8: "someone always uses us, and we use others when we become employers. It is a common strategy "employer-employee."

Coachee_10: "It was, it is, and it will be. I am saying frankly."

Five from thirteen respondents answered that nothing has changed in "Using other people" strategy utilisation after coaching cooperation. One coachee decided to avoid this strategy after coaching. 
Actions Regardless Circumstances. Five out of thirteen participants reported that nothing has changed in this strategy. Another for respondents said that they realised that this strategy is viable. However, most of them were leaning towards the thought that a person should act regardless of internal obstacles rather than external.

Coachee_5: "After our coaching sessions, I would like to prove that I can."

Coachee_6: "I consider it as action regardless circumstances - when I did not have time when I got tired at work $\langle\ldots>$, but despite this, I dedicated some time to what is important for me."

Coachee_10: "Maybe I started to act a little bit regardless of my limiting believes. Sometimes I say to myself: "You have to do it, and after you will see such a good result."

Coachee_13: "I realised that sometimes you need to be patient, you need to overcome yourself to achieve a result. Thus, actions regardless of your laziness, could be viable."

One responded said that certain conditions should be considered while acting in such a way because sometimes you could not see your own mistakes or inefficacy.

Coachee_8: "You can act regardless of circumstances but with certain conditions. I was acting regardless views of my environment for two years, but our coaching cooperation showed some moments where I did not perfect."

One participant responded that she does not want to act against something because it takes much energy.

Coachee_7: "I do not want to act against anything < ... > this is unjustified energy consumption."

The third and the last sector where we can observe social-psychological outcomes of coaching cooperation could be found in such categories as the satisfaction of coaching request, knowledge and skills, self-understanding, self-confidence, self-efficacy, self-regulation, communication.

The satisfaction of coaching request. Six out of thirteen respondents answered that their needs were totally satisfied during coaching cooperation.

Coachee_3: They were satisfied as needed. I started to analyse more. I made notes, and then looked them through I realised that I needed to work with you and really look from another side. $<\ldots>$ Those needs were satisfied...

Coachee_4: Yes. The experience itself was new for me, and I did not know what to expect, but I got a positive result.

Coachee_5: I understood coaching practice and its benefits, and I got certain results which are very important and useful for me.

Coachee_7: I think yes.

Coachee_11: I could say that my tiny request was satisfied.

Coachee_13: Yes, my needs were satisfied.

Three respondents said that coaching cooperation exceeded their expectations, and they got even more than they planned.

Coachee_6: It was more than just satisfaction. I had totally disorientation, disorganisation and disproportion of my time spending $<\ldots>$ cooperating with you, I started to notice that life is not passing by anymore.

Coachee_8: Yes, totally and even more.

Coachee_12: My needs were totally satisfied. Except for business issues, we also considered topics connected with motivation, planning, relations et cetera. Thus, I can tell that I was $200 \%$ satisfied.

Three participants reported partial satisfaction of their requests. The reasons for such an answer were different. One respondent said that his solving of his request needs time and participation of other people. Another one confessed that she has problems with request satisfaction. By the way, this respondent is one of two who were not ready for coaching cooperation and had false expectations towards it. The third respondent explained that a person could never be $100 \%$ satisfied and evaluated her coaching request satisfaction for $80 \%$.

Coachee_1: the need itself was not satisfied. However, it does not depend on you or me; it depends on other people. If to consider a need in information, patterns or other views on the problem, it was satisfied.

Coachee_2: I have another problem - my needs identification. I have problems with requests. Nevertheless, if during the coaching there was a question it was solved. 
Coachee_10: Globally saying, if not you, I never could promote as far as I did. In percentage terms, it is $80 \%$ because human never could be $100 \%$ satisfied. However, there was a huge step forward.

Only one person reported the absence of results. Such answer could be explained with two reasons: the first one is that this coachee was not ready for coaching cooperation, second - the request was connected with own business launch, and as far as our coaching cooperation occurred at the time of COVID-19 lockdown there was no opportunity to implement steps designed during coaching sessions (for example, firm registration, meeting potential clients and site assessment)

Coachee_9: It is hard to say. There are no results yet.

Knowledge and skills. All participants reported acquiring new skills and knowledge, even those who had not the satisfaction of coaching request or had partially satisfaction. Among the skills are skills of analysis, situation evaluation and different decisions search.

Coachee_3: The skill of analysis $<\ldots$.. >everyday needed life skill. That what I gained.

Coachee_12: Skills of planning and new decisions search.

Coachee_4: Yes, this diversified view on a situation when you look at two sides, what could happen and what could not if I will or will not do.

Some respondents reported gaining communication skills:

Coachee_1: I got skills (patterns) of communication.

Coachee_7: Skill to consider everyone as a partner of cooperation and from the view of partnership.

Some participants reported the appearance of skill to be a coach to oneself and use all those techniques provided during the coaching cooperation.

Coachee_10: All those techniques which you gave me I periodically use.

Coachee_13: The primary skill is to observe a situation from different angles. To ask myself questions which will help me to find a decision.

Several respondents reported about the attainment of new knowledge about themselves or the topic of their concern.

Coachee_2: (I got) some technical knowledge connected with Facebook.

Coachee_5: < .. > I defined what keeps me from getting success.

Coachee_6: $<\ldots>$ procrastination is not so scared. I do not waste time now at all.

$<\ldots>$ understanding what I want. It is much easier now to identify my needs.

Coachee_8: < ..> Now I know what I do not know. Now I know where to dig, where to search.

$<\ldots>$ Now I started Instagram advertisement course.

Coachee_9: I depicted the image of what I need to do, and I will do it.

Coachee_11: (I understood) that it is useful to discuss a situation with someone else.

The improvement of self-understanding reported twelve participants out of thirteen. Only one respondent (who were not ready for coaching and whose request was connected with the launch of his own business, which was impossible because of the lockdown start) reported the absence of selfunderstanding changes.

Coachee_8: I think it was improved. I managed it. I needed support which you provided me.

Coachee_11: You asked me questions - directed or such that made me think. <... and you launch processes for self-research. Any research brings results.

The increase of self-confidence reported nine respondents out of thirteen. Three participants said that they still need improvement or work on self-confidence. One person reported the absence of changes.

Coachee_3: Self-confidence came. It changed dramatically. Self-examination became very useful. I started to think more.

Coachee_5: It changed because I understood that I keep me from achieving results. $<\ldots>$ it means that if I would not handicap myself, I could become more successful.

Self-efficacy. Six out of thirteen participants reported the improvement in such a sphere as self-efficacy after coaching cooperation.

Coachee_8: I could say that it increased $<\ldots>$ We highlighted those goals which I need to achieve. If you remember, to enhance competency in certain moments. Thus, I think that selfefficacy definitely increased because we worked through my weak moments and set the goals.

Coachee_11: I think that with self-efficacy - yes. At least now there exist many things which are performed day by day in household and professional spheres. 
Four respondents said that there are some changes, but self-efficacy still need further improvement.

Coachee_10: Here, I have gaps, of course. It enhanced by 40\%. However, I need to work on it.

Three persons reported no changes in self-efficacy or said that it is hard to answer now. One of them said that it does not depend on coaching.

Coachee_1: it does not depend on coaching. When you beat head against the wall sooner or later the question "Is it any good doing it?" occurs.

The increase of self-regulation reported ten out of thirteen participants. Three participants marked no changes in self-regulation. Two of them were those who were not ready for coaching.

Coachee_1: It (self-regulation) became better. I do not blow up immediately anymore.

Coachee_5: I think that it (self-regulation) became better judging what was happening during the quarantine and how it could occur without coaching sessions.

Coachee_10: Yes. Very good - 70-80\%.

The last sub-category changes in which we asked our participants to evaluate was a subcategory of communication. Ten out of thirteen respondents reported an increase in communication skills after coaching. Other three respondents reported no communication skills changes because of the absence of opportunity to communicate face to face (lockdown), the absence of request and work on communication subject, and the absence of problems connected with communication.

Coachee_4: (coaching) helped. I had a very tough conversation with my family and I the credit goes to coaching as well.

Coachee_8: Yes, it definitely changed for better and even showed a particular result.

Coachee_12: There is an enhancement because our interaction showed me how to communicate effectively with others.

As we can see from this research coaching cooperation has outcomes for IDPs on both intrapersonal and interpersonal levels which is proved with analysis of quantitative and qualitative data. However, there is a matter of discussion. First of all, we can notice that at least two of thirteen participants were not ready for coaching cooperation. What of course, minimised the coaching outcomes. Maybe for dealing with this situation except the grounding of participation from coachees, there should also be a socialisation in method session. From our perspective, such an approach could decrease false expectations and give additional engagement from the very beginning. Secondly, maybe it will be useful to mix coaching with some other (more structured) methods that will influence definite scales and forecast results and make it more precise. Thirdly, coaching sessions were conducted during the lockdown due to the COVID-19 pandemic situation. This factor, in our view, influenced coaching results. Participants also mention this influence.

Conclusions. Coach-IDP cooperation itself could be useful for coachee's development of social skills because in such case coach could be considered as a role model. Furthermore, even from such interaction, coachee could take some references for the building of benefiting relationships that are a background for utilising of social-psychological strategies for life successfulness.

Coaching could deal with both intrapersonal and interpersonal issues. The results of the quantitative analysis showed a significant level of difference in "before" and "after" levels of such scales as Social Desirability, Relationships with Close People, Leisure, Live Successfulness (overall test result), Factor P (inclination towards antisocial behaviour), Reflection, Stress-resistance. In every case, we see enhancement of the situation, but due to the scoring systems of different scales in some cases, we observed an increase of values and in some cases, a decrease of values. Qualitative results to our mind correlate with quantitative and are a good base for explaining changes that occurred during coaching cooperation. First of all, we see the concretisation of life successfulness understanding after coaching. Secondly, we see changes in social-psychological strategies for life successfulness understanding and utilisation. Thirdly, we can see that coaching requests were totally or partially satisfied in most cases. Fourthly, we see changes in such categories as gaining knowledge and skills, increasing self-understanding, self-confidence, self-efficacy, self-regulation, and developing communicative skills. Thus, coaching showed its effectiveness as a mean of intervention in cases connected with life reconstruction and adaptation after forced relocation. 


\section{REFERENCES}

1. Nareiman N. Abdul Moeti, Kim Margaret B. Amora. (2019) Coaching: A Strategic Imperative to Enhancing Skills of Emerging Leaders. Organization Leadership and Development Quarterly. Vol.1. Iss. 2., 33-40.

2. ICF (2020) a. Code of Ethics [Electronic resource]. URL: https://coachfederation.org/code-of-ethics.

3. Passmore J., Fillery-Travis A. (2011) A critical review of executive coaching research: A decade of progress and what's to come. Coaching: An International Journal of Theory, Practice \& Research, 4 (2), 70-88.

4. Brotman, L. E., Liberi, W. P., \& Wasylyshyn, K. M. (1998). Professional coaching: The need for standards of competence. Consulting Psychology Journal: Practice and Research, 40(1), 40-46.

5. Koortzen, P., Oosthuizen, R. (2010). A competence executive coaching model. SA Journal of Industrial Psychology, 36(1).

6. McGovern, J., Lindemann, M., Vergara, M., Murphy, S., Barker, L., \& Warrenfeltz, R. (2001). Maximizing the impact of professional coaching: Behavioral change, organizational outcomes, and return on investment. The Manchester Review, 6(1), 1-9.

7. Stevens, J. H., Jr. (2005). Professional coaching from the professional's perspective. Consulting Psychology Journal: Practice and Research, 57(4), 274-285.

8. Correia, M. C., Dos Santos, R. N. and Passmore, J. (2016) Understanding the coach coachee client relationship: a conceptual framework for executive coaching. International Coaching Psychology Review, 11 (1). pp. 623.

9. de Haan, E., Grant, A. M., Burger, Y., \& Eriksson, P.-O. (2016). A large-scale study of executive and workplace coaching: The relative contributions of relationship, personality match, and self-efficacy. Consulting Psychology Journal: Practice and Research, 68(3), 189-207. https://doi.org/10.1037/cpb0000058

10. Boysen, S. M. (2018) Coaching Effectiveness: Coach and Coachee Characteristics that Lead to Success. Philosophy of Coaching: An International Journal. Vol. 3, No. 2, November 2018, 6-26. http://dx.doi.org/10.22316/poc/03.2.02

11. Borovynska, I. Ye. (2020). Coaching as a mean of social-psychological strategies for life successfulness activation among internally displaced persons with low level of life successfulness: possibilities and limitations. Theory and practice of modern psychology. Iss. 1. Vol. 3., 21-27. DOI: 10.32840/2663-6026.2020.1-3.3

12. ICF (2020) b. Sample Coaching Agreement [Electronic resource]. URL: https://coachfederation.org/app/uploads/2017/11/SampleCoachingAgreement.pdf

13. Fetiskin N. P. (2002) Sotsialno-psichologicheskaya diagnostical lichnosti i malykh grup. (Sochialpsychological diagnostic of person's and small groups' development). Moskva: Institut psichoterapii. 490.

14. Malkina-Pykh I. G. (2005) Psichosomatika: Spravochnik prakticheskogo psichologa (Psychosomatic: handbook of practical psychologist). Moskva: Eksmo. 992. 